\title{
Validation and invalidation of SARS-CoV-2 papain-like protease inhibitors
}

\author{
Chunlong $\mathrm{Ma}^{\dagger}{ }^{\dagger}$ Jun Wang ${ }^{\dagger, *}$ \\ ${ }^{\dagger}$ Department of Pharmacology and Toxicology, College of Pharmacy, The University of Arizona, \\ Tucson, Arizona 85721, United States
}

${ }^{*}$ Corresponding author:

Jun Wang, Tel: 520-626-1366, Fax: 520-626-0749, email: junwang@pharmacy.arizona.edu 


\begin{abstract}
SARS-CoV-2 encodes two viral cysteine proteases, the main protease $\left(\mathrm{M}^{\text {pro }}\right)$ and the papain-like protease $\left(\mathrm{PL}^{\text {pro }}\right)$, both of which are validated antiviral drug targets. The $\mathrm{PL}^{\text {pro }}$ is involved in the cleavage of viral polyproteins as well as immune modulation through removing ubiquitin and interferon-stimulated gene product 15 (ISG15) from host proteins. Therefore, targeting PL pro might be a two-pronged approach. Several compounds including YM155, cryptotanshinone, tanshinone I, dihydrotanshinone I, tanshinone IIA, SJB2-043, 6-thioguanine, and 6mercaptopurine were recently identified as SARS-CoV-2 PL ${ }^{\text {pro }}$ inhibitors through highthroughput screening. In this study, we aim to validate/invalidate the reported $\mathrm{PL}^{\text {pro }}$ inhibitors using a combination of $\mathrm{PL}^{\text {pro }}$ target specific assays including enzymatic FRET assay, thermal shift binding assay (TSA), and the cell based FlipGFP assay. Collectively, our results showed that all compounds tested either did not show binding or led to denaturation of the $\mathrm{PL}^{\text {pro }}$ in the TSA binding assay, which might explain their weak enzymatic inhibition in the FRET assay. In addition, none of the compounds showed cellular inhibition of $\mathrm{PL}^{\text {pro }}$ as revealed by the FlipGFP assay. Therefore, more efforts are needed to search for specific and potent SARS-CoV-2 PL ${ }^{\text {pro }}$ inhibitors.
\end{abstract}

Keywords: SARS-CoV-2, papain-like protease, GRL0617, FlipGFP, antiviral 


\section{Introduction}

The COVID-19 pandemic is a timely reminder for the urgent need of antivirals, especially broadspectrum antivirals that could be used as the first line defense against not only current pandemic but also future pandemics. ${ }^{1}$ SARS-CoV-2, together with SARS-CoV and MERS-CoV are the three coronaviruses in the $\beta$-coronavirus family that caused pandemic/epidemic in human. $^{2}$ The SARS-CoV the MERS-CoV had higher mortality rates than SARS-CoV-2. ${ }^{3}$ However, SARS-CoV-2 has a much higher transmission rate than SARS-CoV and MERS-CoV, which leads to far greater infection cases and death tolls.

SARS-CoV-2 shares $86 \%$ sequence identity with SARS-CoV, which renders the rapid understanding of its viral pathogenicity feasible. SARS-CoV-2 expresses two viral proteases during the viral replication, the main protease ( $\mathrm{M}^{\text {pro }}$; nsp5) and the papain-like protease $\left(\mathrm{PL}^{\text {pro }}\right.$; nsp3). Both are cysteine proteases and have been validated as antiviral drug targets. ${ }^{4-6} \mathrm{PL}^{\text {pro }}$ and $\mathrm{M}^{\text {pro }}$ cleave the viral polyproteins pp1a and pp1ab at 3 and more than 11 sites, respectively, resulting in individual functional viral proteins for the assembly of viral replication complex. Compared to $\mathrm{PL}^{\text {pro }}, \mathrm{M}^{\text {pro }}$ is a more amenable drug target and has been the central focus of COVID-19 antiviral discovery. Structurally disparate compounds have been reported as $\mathrm{M}^{\text {pro }}$ inhibitors from either drug repurposing screening or rational design..$^{7-8}$ Although a large number of reported $\mathrm{M}^{\text {pro }}$ inhibitors were later proven to be promiscuous cysteine modifiers, ${ }^{9-13}$ several $\mathrm{M}^{\text {pro }}$ inhibitors have been validated as specific inhibitors and have shown in vivo antiviral efficacy in animal model studies. ${ }^{14-18}$ Significantly, two Pfizer $\mathrm{M}^{\text {pro }}$ inhibitors PF-07304814 and PF-07321332 are advanced to human clinical trials. ${ }^{17-18} \mathrm{PL}^{\text {pro }}$ is second viral cysteine protease that cleaves the viral polypeptide at three different sites during viral replication. In addition, $\mathrm{PL}^{\text {pro }}$ modulates host immune response by cleaving ubiquitin and ISG15 (interferon-induced gene 15) from host proteins. ${ }^{19-21}$ In contrast to $M^{\text {pro }}$ inhibitors, the development of $\mathrm{PL}^{\text {pro }}$ inhibitors is still at its infancy. ${ }^{22}$ The most promising PL ${ }^{\text {pro }}$ inhibitors are the naphthalene-based GRL0617 series of compounds (Figure 1A). ${ }^{6,21,23-25}$ However, their antiviral potency and pharmacokinetic properties need to be further optimized for the in vivo animal model study. $\mathrm{PL}^{\text {pro }}$ specifically recognize the $\mathrm{P} 1-\mathrm{P} 4$ sequence Gly-Gly-X-Leu that is conserved among the nsp1/2, nsp2/3, and nsp3/4 cleavage sites at the viral polyprotein. ${ }^{26}$ The featureless P1 and P2 binding pockets present a grand challenge in developing potent $P L^{\text {pro }}$ inhibitors. ${ }^{26}$ As the drug-binding site is far

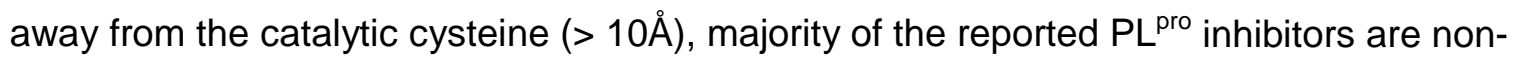
covalent inhibitors. ${ }^{7}$ Although peptidomimetic covalent $\mathrm{PL}^{\text {pro }}$ inhibitors have been reported, no antiviral activity was shown. ${ }^{26}$ To identify additional novel $\mathrm{PL}^{\text {pro }}$ inhibitors, several high- 
throughput screenings have been performed and structurally disparate compounds were found to inhibit PL ${ }^{\text {pro }}$ (Figure 1B). ${ }^{27-30}$ To evaluate whether any of the identified candidates might worth further pursuing, we are interested in validating/invalidating the reported $\mathrm{PL}^{\text {pro }}$ inhibitors using a combination of orthogonal assays including the activity-based FRET enzymatic assay, the thermal shift binding (TSA) assay, and the cell-based FlipGFP assay. Collectively, in contrast to the literature reported results, our data showed that the examined non-GRL0617-based PL pro inhibitors (Figure 1B) had weak enzymatic inhibition and no cellular PL ${ }^{\text {pro }}$ inhibition, therefore they should not be referenced as $\mathrm{PL}^{\text {pro }}$ inhibitors.

A

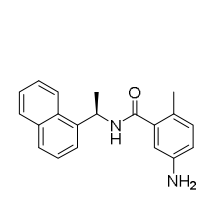

GRL0617
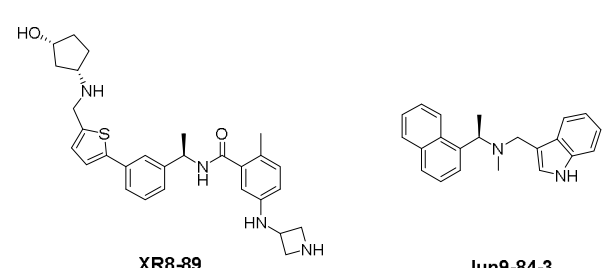

Jun9-84-3

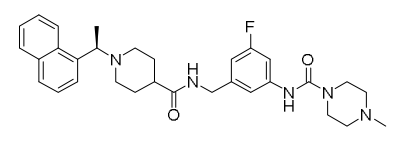

Compound 19

B
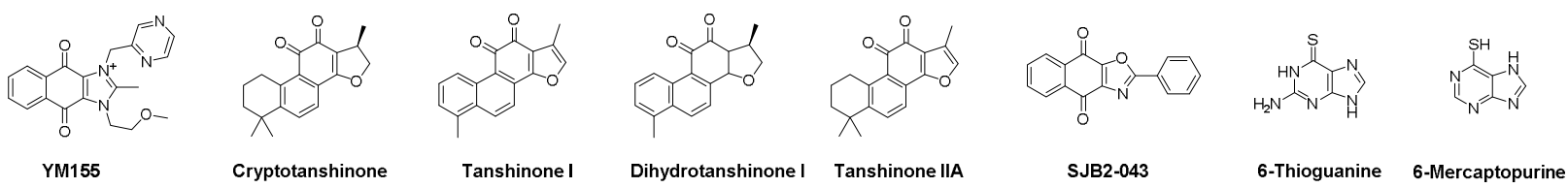

Figure 1. SARS-CoV-2 PL ${ }^{\text {pro }}$ inhibitors. (A) GRL0617 analogs. (B) Structurally disparate PL ${ }^{\text {pro }}$ inhibitors identified from high-throughput screening or drug repurposing.

\section{Results}

Through a high-throughput screening of over 6,000 bioactive compounds using a quenched fluorescent substrate RLRGG-AMC, Zhao et al identified four compounds YM155, cryptotanshinone, tanshinone I, and GRL0617 as potent PL ${ }^{\text {pro }}$ inhibitors with $\mathrm{IC}_{50}$ values from 1.39 to $5.63 \mu \mathrm{M}^{29}$ In plaque reduction assay, YM155, cryptotanshinone, and tanshinone I inhibited SARS-CoV-2 replication in Vero E6 cells with $\mathrm{EC}_{50}$ values of $0.17,0.70$, and $2.26 \mu \mathrm{M}$, respectively. The X-ray crystal structure of SARS-CoV-2 PL ${ }^{\text {pro }}$ with YM155 was solved (PDB: 7D7L), revealing three different binding sites in the thumb domain, the zinc-finger motif, and the substrate-binding pocket. In the substrate binding pocket, YM155 induces a conformational change of Y268 on the BL2 loop and forms a m-stacking interaction, which is similar to the binding mode of GRL0617. Binding at the thumb domain likely impedes the interaction between 
bioRxiv preprint doi: https://doi.org/10.1101/2021.11.04.467342; this version posted November 5, 2021. The copyright holder for this preprint

(which was not certified by peer review) is the author/funder, who has granted bioRxiv a license to display the preprint in perpetuity. It is made available under aCC-BY 4.0 International license.

$\mathrm{PL}^{\text {pro }}$ and ISG15. The third binding site at the zinc-finger domain might perturb its stability, however, this mechanism remains to be validated. 
bioRxiv preprint doi: https://doi.org/10.1101/2021.11.04.467342; this version posted November 5, 2021. The copyright holder for this preprint

(which was not certified by peer review) is the author/funder, who has granted bioRxiv a license to display the preprint in perpetuity. It is made available under aCC-BY 4.0 International license.

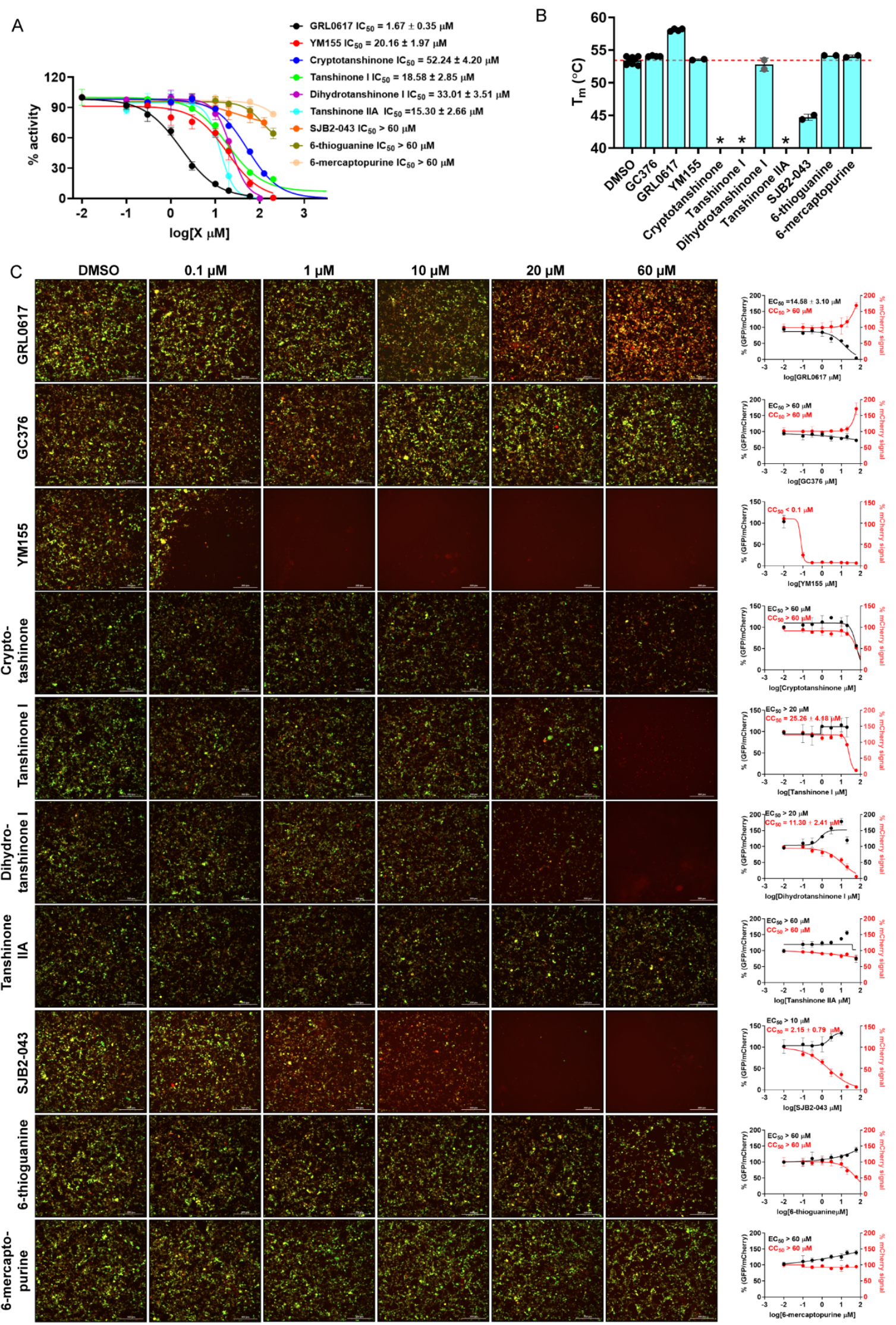


Figure 2. Pharmacological characterization of SARS-CoV-2 PL ${ }^{\text {pro }}$ inhibitors. (A) Enzymatic inhibitory activity against SARS-CoV-2 PL ${ }^{\text {pro }}$ in FRET-based assay. (B) Thermal shift assay of the SARS-CoV-2 PL pro inhibitors in stabilizing the SARS-CoV-2 $\mathrm{PL}^{\text {pro } . ~ * ~ m e a n s ~ m e l t i n g ~ p e a k ~ w a s ~}$ not observed the in the presence of the inhibitor. The dashed red line indicates the mean of SARS-CoV-2 PL ${ }^{\text {pro }} \mathrm{T}_{\mathrm{m}}$ in the absence of testing inhibitors. (C) Cell-based FlipGFP assay for the quantification of the cellular activity of SARS-CoV-2 PL pro inhibitors. Representative images of FlipGFP PL pro assay with the positive control GRL0617 and the negative control GC-376. Dose-response curves of the ratio of GFP/mCherry fluorescence with SARS-CoV-2 PL pro inhibitors were plotted at right side column; mCherry signal alone was used to normalize protein expression level or calculate compound cytotoxicity.

In our validation study, the positive control GRL0617 showed similar enzymatic inhibition with an $\mathrm{IC}_{50}$ of $1.67 \mu \mathrm{M}$ (Figure 2A). However, we found that the enzymatic inhibition potency for YM155, cryptotanshinone, and tanshinone I against $\mathrm{PL}_{\text {pro }}$ were $\sim 10$-fold less active than previously reported and the $\mathrm{IC}_{50}$ values from our study were $20.16,52.24$, and $18.58 \mu \mathrm{M}$, respectively (Figure 2A and Table 2). The discrepancy might be caused by the different substrates used. In Zhao et als study, RLRGG-AMC was used, while we used a FRET substrate DabcylFTLRGG/APTKV-Edans which spans both the P and P' sites. Nevertheless, in the thermal shift binding assay, YM155 had no effect on the stability of $\mathrm{PL}^{\text {pro }}$, while cryptotanshinone and tanshinone I caused destabilization of the protein (Figure 2B and Table 2). In the cell-based FlipGFP assay, ${ }^{6}$ the result for YM155 was not conclusive as it was cytotoxic to the 293T cells (Figure 2C). Both cryptotanshinone and tanshinone I were not active $\left(\mathrm{EC}_{50}>60 \mu \mathrm{M}\right)$ (Figure 2C). Overall, our results indicate that cryptotanshinone and tanshinone I were not specific $\mathrm{PL}^{\text {pro }}$

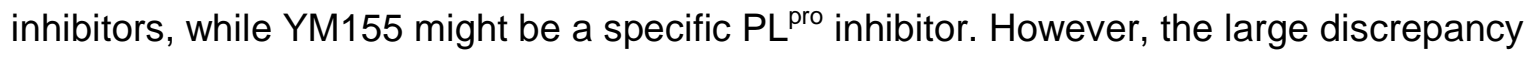
between the enzymatic inhibition $\left(\mathrm{IC}_{50}=20.16 \mu \mathrm{M}\right)$ and the cellular antiviral activity of YM155 $\left(E_{50}=0.17 \mu \mathrm{M}\right)$ suggest that the other mechanisms might contribute to its potent antiviral activity against SARS-CoV-2. 
Table 1. Validation/invalidation of SARS-CoV-2 PL ${ }^{\text {pro }}$ inhibitors.

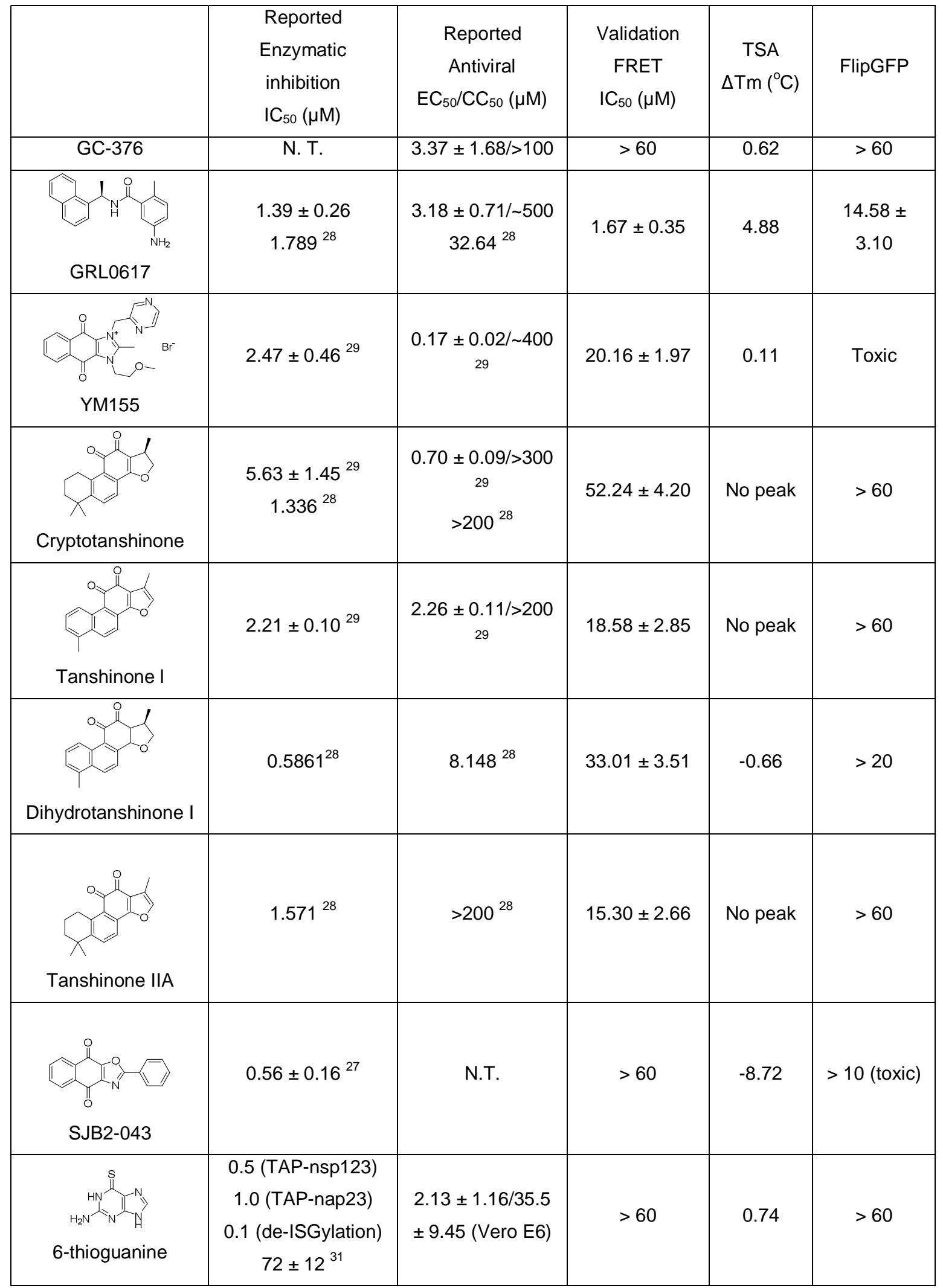




\begin{tabular}{|l|l|l|l|l|l|}
\hline \multirow{2}{*}{\begin{tabular}{c} 
N-mercaptopurine \\
\hline
\end{tabular}} & N.T. & N.T. & $>60$ & 0.60 & $>60$ \\
\hline
\end{tabular}

N.T. = not tested

In another study, cryptotanshinone, together with two analogs dihydrotanshinone I and

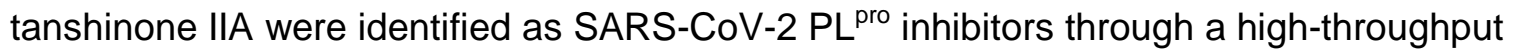
screening (HTS). ${ }^{28}$ Cryptotanshinone, dihydrotanshinone I and tanshinone IIA inhibited SARSCoV-2 PL pro with $\mathrm{IC}_{50}$ values of $1.336,0.5861$, and $1.571 \mu \mathrm{M}$, respectively. It is noted that no complete inhibition was observed for cryptotanshinone, therefore the $\mathrm{IC}_{50}$ value might not be trustworthy. To rule out the possibility of fluorescence interference, these compounds were also tested in the gel-based PL ${ }^{\text {pro }}$ assay using the GST-nsp2/3-MBP substrate. All these compounds inhibited the digestion of the protein substrate with tanshinone IIA and cryptotanshinone showing higher potency than dihydrotanshinone I. Dihydrotanshinone I also inhibited the deubiquitinase and delSGlase activities of $\mathrm{PL}^{\text {pro }}$ in the gel-based digestion assay. In the SARSCoV-2 antiviral assay in Vero E6 cells, dihydrotanshinone I had the highest potency with an $\mathrm{EC}_{50}$ of $8.148 \mu \mathrm{M}$, while cryptotanshinone and tanshinone I were not active $\left(\mathrm{EC}_{50}>200 \mu \mathrm{M}\right)$. The lack of correlation between the enzymatic inhibition and the cellular antiviral activity might due to cell membrane permeability or off-target effects.

In our validation study, both dihydrotanshinone I and tanshinone IIA were greater than 10-fold less potent in the enzymatic assay with $\mathrm{IC}_{50}$ values of 33.01 and $15.30 \mu \mathrm{M}$, respectively (Figure 2A and Table 2). Dihydrotanshinone I did not bind to $\mathrm{PL}^{\text {pro }}$ as shown by the results from the TSA assay (Figure 2B). Tanshinone IIA led to denaturation of the protein (no melting peak). Dihydrotanshinone I and tanshinone IIA were not active in the FlipGFP assay $\left(\mathrm{IC}_{50}>20 \mu \mathrm{M}\right)$ (Figure 2C). Overall, it appears that dihydrotanshinone I and tanshinone IIA were not specific

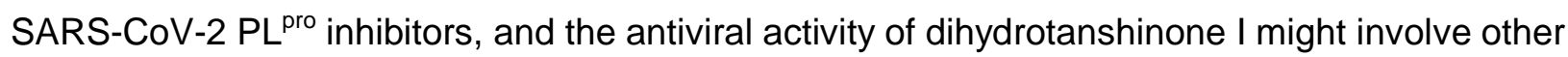
mechanisms.

Cho et al reported SJB2-043 a SARS-CoV-2 PL pro inhibitor through a focused screening of a library of deubiquitinase inhibitors. ${ }^{27}$ SJB2-043 did not achieve complete inhibition and had an apparent $\mathrm{IC}_{50}$ of $0.56 \mu \mathrm{M}$. When Ub-AMC was used as a substrate, the $\mathrm{IC}_{50}$ of SJB2-043 was $0.091 \mu \mathrm{M}$. Similarly, no complete inhibition was achieved. In comparison, the positive control GRL0617 showed complete inhibition when both Z-LRGG-AMC and Ub-AMC were used as 
substrates, and the $\mathrm{IC}_{50}$ values were 1.37 and $1.80 \mu \mathrm{M}$, respectively. Molecular docking suggests that SJB2-043 binds to an allosteric site in $\mathrm{PL}^{\text {pro. }}$.

When repeated in our assay, SJB2-043 did not inhibit the SARS-CoV-2 PL ${ }^{\text {pro }}\left(\mathrm{IC}_{50}>60 \mu \mathrm{M}\right)$ (Figure 2A). The discrepancy might be caused by different methods used for data fitting. In our assay, SJB2-043 did not achieve more than 50\% inhibition at the highest concentration tested, which is $60 \mu \mathrm{M}$, therefore we deemed the $\mathrm{IC}_{50}$ greater than $60 \mu \mathrm{M}$. In the TSA binding assay, SJB2-043 led to the destabilization of $\mathrm{PL}^{\text {pro }}\left(\Delta \mathrm{T}_{\mathrm{m}}=-8.72 \mu \mathrm{M}\right)$ (Figure $\left.2 \mathrm{~B}\right)$. The result from the FlipGFP assay was not conclusive as SJB2-043 was cytotoxic (Figure 2C). Overall, SJB2-043

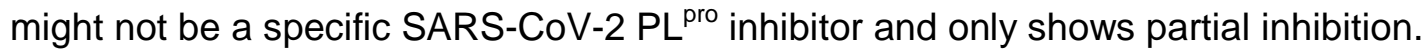

Swaim et al reported that 6-thioguanine inhibited SARS-CoV-2 replication in Vero E6 cells with an $\mathrm{EC}_{50}$ of $2.13 \mu \mathrm{M}^{30}$ Mechanistic studies showed that 6-thioguanine had potent inhibition against $\mathrm{PL}^{\text {pro }}$ in cells and in vitro using the TAP-nsp123, TAP-nsp23, and Pro-ISG15-HA substrates. Another study from Fu et al showed that 6-thioguanine inhibited SARS-CoV-2 PL ${ }^{\text {pro }}$ in the enzymatic assay with an $\mathrm{IC}_{50}$ of $72 \mu \mathrm{M} .{ }^{31}$ In our study, 6 -thioguanine was not active in the FRET-based enzymatic assay $\left(\mathrm{IC}_{50}>60 \mu \mathrm{M}\right)$ (Figure 2A). 6-thioguanine also did not show binding in the TSA assay nor inhibition in the FlipGFP assay (Figures $2 \mathrm{~B}$ and $2 \mathrm{C}$ ). As such, the antiviral activity of 6 -thioguanine might involve other mechanisms. 6 mercaptopurine, which is an analog of 6-thioguanine, was similar not active in all three assays (Figure 2 and Table 2). Therefore, it can be concluded that 6-thioguanine and 6-mercaptopurine were not SARS-CoV-2 $\mathrm{PL}^{\text {pro }}$ inhibitors.

\section{Discussion}

Drug repurposing is often viewed as a fast-track drug discovery approach since it can potentially bypass the length safety tests before entering clinical trials. ${ }^{32}$ However, we should remain cautiously optimistic about this approach. ${ }^{33}$ Since the existing bioactive compounds were not specifically designed and optimized for the screening drug target, the identified hits need to be vigorously characterized to validate the target specificity. The SARS-CoV-2 $\mathrm{M}^{\text {pro }}$ and $\mathrm{PL}{ }^{\text {pro }}$ are cysteine proteases which are prone to non-specific inhibition by alkylating agents or re-dox cycling compounds. Indeed, our recent studies, together with others, have collectively shown that a number of reported $\mathrm{M}^{\text {pro }}$ inhibitors including ebselen, carmofur, disulfiram, and shikonin are promiscuous non-specific cysteine protease inhibitors. ${ }^{9-13}$ With our continuous interest in validation/invalidation of literature reported $\mathrm{M}^{\text {pro }}$ and $\mathrm{PL}^{\text {pro }}$ inhibitors, in this study we 
characterized eight $\mathrm{PL}^{\text {pro }}$ inhibitors using a combination of FRET-based enzymatic assay, TSA binding assay, and the cell-based FlipGFP PL ${ }^{\text {pro }}$ assay. It is expected that specific inhibitors will show consistent results from all three assays. Among the compounds tested, cryptotanshinone, tanshinone I, dihydrotanshinone I, and tanshinone IIA were also previously reported as potent SARS-CoV PL ${ }^{\text {pro }}$ inhibitors with $\mathrm{IC}_{50}$ values ranging from 0.8 to $8.8 \mu \mathrm{M}^{34}$ Interesting, they also inhibited SARS-CoV $\mathrm{M}^{\text {pro }}$ with $\mathrm{IC}_{50}$ values ranging from 14.4 to $226.7 \mu \mathrm{M}$. Since $\mathrm{M}^{\text {pro }}$ and $\mathrm{PL}^{\text {pro }}$ do not share structural and sequence similarities, the dual inhibitory activities of these tanshinones, coupled with the weak PL ${ }^{\text {pro }}$ enzymatic inhibition from our study, suggest that they might have a promiscuous mechanism of action.

Similarly, 6-thioguanine and 6-mercaptopurine were previously reported as SARS-CoV PL ${ }^{\text {pro }}$ inhibitors with $\mathrm{IC}_{50}$ values of 5.0 and $21.6 \mu \mathrm{M}$, respectively. ${ }^{35-36}$ In addition, Cheng et al reported that 6-thioguanine and 6-mercaptopurine are competitive inhibitors of MERS-CoV PL ${ }^{\text {pro }}$ with $\mathrm{IC}_{50}$ values of 24.4 and $26.9 \mu \mathrm{M}$, respectively. ${ }^{37}$ In contrast, YM155 and SJB2-043 were not previously shown to inhibit SARS-CoV PL ${ }^{\text {pro }}$. Given the $82.6 \%$ sequence similarity between SARS-CoV-2 and SARS-CoV PL ${ }^{\text {pro }}$, it appears not a surprising finding that cryptotanshinone, tanshinone I, dihydrotanshinone I, tanshinone IIA, and 6-thioguanine were also reported as SARS-CoV-2 PL pro inhibitors from recent studies. Nevertheless, our independent study has shown that all eight compounds had drastically reduced enzymatic inhibition against $\mathrm{PL}^{\text {pro }}$ compared to reported values (Table 1). In addition, all compounds either had no effect or destabilize $\mathrm{PL}^{\text {pro }}$ as shown by the TSA binding assay (Table 1). Furthermore, cryptotanshinone, tanshinone I, dihydrotanshinone I, tanshinone IIA, 6-thioguanine, and 6-mercaptopurine were not active in the FlipGFP PL ${ }^{\text {pro }}$ assay, suggesting there is a lack of cellular $\mathrm{PL}^{\text {pro }}$ target engagement. YM155 and SJB2-043 were cytotoxic, therefore it remains unknown whether they can selectively bind to $\mathrm{PL}^{\text {pro }}$ inside the cell. Overall, our study calls for more stringent validation of the reported SARS-CoV-2 PL ${ }^{\text {pro }}$ inhibitors to avoid the failure in the follow up lead optimization and translational development.

\section{Materials and methods}

Chemicals and peptide substrate. The SARS-CoV-2 PL pro substrate Dabcyl-FTLRGG/APTKVEdans was synthesized by the solid-phase synthesis and the detailed procedure was described in our previous publication. , $^{10}$ The testing compounds were ordered from the following sources: tanshinone I (Sigma T5330), dihydrotanshinone I (Sigma D0947), tanshinone IIA (Sigma 
SML2517), cryptotanshinone (Sigma C5624), YM-155 (APExBIO A4221), and SJB2-043 (APExBIO A3823).

SARS-CoV-2 PL ${ }^{\text {pro }}$ expression and purification. SARS-CoV-2 papain-like protease (PL ${ }^{\text {pro }}$ ) gene (ORF 1ab 1564-1876) from strain BetaCoV/Wuhan/WIV04/2019 with E. coli codon optimization was ordered from GenScript in the $\mathrm{pET} 28 \mathrm{~b}(+)$ vector. The detailed expression and purification procedures were previously described. ${ }^{6,10}$

FRET-Based enzymatic assay. For the $\mathrm{IC}_{50}$ measurement with FRET-based assay, the reaction was carried out in 96-well format with $100 \mu \mathrm{l}$ of $200 \mathrm{nM} \mathrm{PL}{ }^{\text {pro }}$ protein in a PL ${ }^{\text {pro }}$ reaction buffer (50 mM HEPES pH 7.5, 5 mM DTT and 0.01\% Triton X-100); $1 \mu$ l of testing compounds at various concentration was added to each well and was incubated at $30^{\circ} \mathrm{C}$ for $30 \mathrm{~min}$. The reaction was initiated by adding $1 \mu \mathrm{l}$ of $1 \mathrm{mM}$ FRET substrate and was monitored in a Cytation 5 image reader with filters for excitation at $360 / 40 \mathrm{~nm}$ and emission at $460 / 40 \mathrm{~nm}$ at $30^{\circ} \mathrm{C}$ for $1 \mathrm{~h}$. The initial velocity of the enzymatic reaction was calculated from the initial 10 min enzymatic reaction. The $\mathrm{IC}_{50}$ was calculated by plotting the initial velocity against various concentrations of testing compounds by use of a four parameters variable slope dose-response curve in Prism 8 software.

Differential Scanning Fluorimetry (DSF). The thermal shift binding assay (TSA) was carried out using a Thermo Fisher QuantStudio 5 Real-Time PCR system as described previously. 6, 10

Cell-Based FlipGFP-PL ${ }^{\text {pro }}$ Assay. Cell-based FlipGFP-PL ${ }^{\text {pro }}$ assay was established as previously described. Briefly, 293T cells were maintained in Dulbecco's modified Eagle's medium (DMEM), supplemented with 10\% heat-inactivated FBS and 1\% penicillin-streptomycin antibiotics in a $37{ }^{\circ} \mathrm{C}$ incubator with $5 \% \mathrm{CO}_{2}$. 96-well Greiner plate (catalog no. 655090) was seeded with 293T cells to overnight 70-90\% confluency. 50 ng of pcDNA3-flipGFP-PLpro-T2AmCherry plasmid and 50 ng of pcDNA3.1-SARS2-PL ${ }^{\text {pro }}$ were used each well in the presence of transfection reagent TransIT-293 (Mirus) per manufacturer protocol. Three hours after transfection, $1 \mu \mathrm{l}$ of testing compound was added to each well at 100 -fold dilution. 2 days after transfection images were obatined with a Cytation 5 imaging reader (Biotek) with GFP and mCherry channels. SARS-CoV-2 PL pro protease activity was evaluated by the ratio of GFP signal intensity over the mCherry signal intensity. The compound FlipGFP-PLP assay $\mathrm{IC}_{50}$ value was calculated by plotting the GFP/mCherry signal to the testing compound concentration with a 
four-parameter variable slope dose-response function in Prism 8. The mCherry signal alone was utilized to determine the compound cytotoxicity.

\section{Corresponding Authors}

Jun Wang - Department of Pharmacology and Toxicology, College of Pharmacy, University of Arizona, Tucson, AZ, 85721, United States; Email: junwang@pharmacy.arizona.edu ORCID: 0000-0002-4845-4621

\section{Authors}

Chunlong Ma - Department of Pharmacology and Toxicology, College of Pharmacy, The University of Arizona, Tucson, Arizona 85721, United States

Jun Wang - Department of Pharmacology and Toxicology, College of Pharmacy, The University of Arizona, Tucson, Arizona 85721, United States

\section{Author Contributions}

C. M. performed the enzymatic assay, thermal shift binding assay, and the FlipGFP assay. J. W. designed and supervised this study. J. W. wrote the manuscript with contribution from C. M.

\section{Acknowledgements}

This research was supported by the National Institutes of Health (NIH) (Grant Al147325, Al157046, and Al158775) and the Arizona Biomedical Research Centre Young Investigator grant (ADHS18-198859) to J.W.

\section{References}

1. Lu, L.; Su, S.; Yang, H.; Jiang, S., Antivirals with common targets against highly pathogenic viruses. Cell 2021, 184 (6), 1604-1620. 
2. Cui, J.; Li, F.; Shi, Z.-L., Origin and evolution of pathogenic coronaviruses. Nat Rev Microbiol 2019, 17 (3), 181-192.

3. Bar-On, Y. M.; Flamholz, A.; Phillips, R.; Milo, R., SARS-CoV-2 (COVID-19) by the numbers. eLife 2020, 9, e57309.

4. Ma, C.; Sacco, M. D.; Hurst, B.; Townsend, J. A.; Hu, Y.; Szeto, T.; Zhang, X.; Tarbet, B.; Marty, M. T.; Chen, Y.; Wang, J., Boceprevir, GC-376, and calpain inhibitors II, XII inhibit SARSCoV-2 viral replication by targeting the viral main protease. Cell Res 2020, 30 (8), 678-692.

5. Sacco, M. D.; Ma, C.; Lagarias, P.; Gao, A.; Townsend, J. A.; Meng, X.; Dube, P.; Zhang, X.; Hu, Y.; Kitamura, N.; Hurst, B.; Tarbet, B.; Marty, M. T.; Kolocouris, A.; Xiang, Y.; Chen, Y.; Wang, J., Structure and inhibition of the SARS-CoV-2 main protease reveal strategy for developing dual inhibitors against M(pro) and cathepsin L. Sci Adv 2020, 6 (50), eabe0751.

6. Ma, C.; Sacco, M. D.; Xia, Z.; Lambrinidis, G.; Townsend, J. A.; Hu, Y.; Meng, X.; Szeto, T.; Ba, M.; Zhang, X.; Gongora, M.; Zhang, F.; Marty, M. T.; Xiang, Y.; Kolocouris, A.; Chen, Y.; Wang, J., Discovery of SARS-CoV-2 Papain-like Protease Inhibitors through a Combination of High-Throughput Screening and a FlipGFP-Based Reporter Assay. ACS Cent Sci 2021, 7 (7), 1245-1260.

7. Ghosh, A. K.; Brindisi, M.; Shahabi, D.; Chapman, M. E.; Mesecar, A. D., Drug Development and Medicinal Chemistry Efforts toward SARS-Coronavirus and Covid-19 Therapeutics. ChemMedChem 2020, 15 (11), 907-932.

8. Xiong, M.; Su, H.; Zhao, W.; Xie, H.; Shao, Q.; Xu, Y., What coronavirus 3C-like protease tells us: From structure, substrate selectivity, to inhibitor design. Med Res Rev 2021, 41 (4), 1965-1998.

9. Ma, C.; Tan, H.; Choza, J.; Wang, Y.; Wang, J., Validation and invalidation of SARSCoV-2 main protease inhibitors using the Flip-GFP and Protease-Glo luciferase assays. Acta Pharm Sin B 2021, 2021.08.28.458041.

10. Ma, C.; Hu, Y.; Townsend, J. A.; Lagarias, P. I.; Marty, M. T.; Kolocouris, A.; Wang, J., Ebselen, Disulfiram, Carmofur, PX-12, Tideglusib, and Shikonin Are Nonspecific Promiscuous SARS-CoV-2 Main Protease Inhibitors. ACS Pharmacol Transl Sci 2020, 3 (6), 1265-1277.

11. Ma, C.; Wang, J., Dipyridamole, chloroquine, montelukast sodium, candesartan, oxytetracycline, and atazanavir are not SARS-CoV-2 main protease inhibitors. Proc Natl Acad Sci U S A 2021, 118 (8), e2024420118.

12. Gurard-Levin, Z. A.; Liu, C.; Jekle, A.; Jaisinghani, R.; Ren, S.; Vandyck, K.; Jochmans, D.; Leyssen, P.; Neyts, J.; Blatt, L. M.; Beigelman, L.; Symons, J. A.; Raboisson, P.; Scholle, M. 
D.; Deval, J., Evaluation of SARS-CoV-2 3C-like protease inhibitors using self-assembled monolayer desorption ionization mass spectrometry. Antiviral Res 2020, 182, 104924.

13. Cao, W.; Cho, C.-C. D.; Geng, Z. Z.; Ma, X. R.; Allen, R.; Shaabani, N.; Vatansever, E. C.; Alugubelli, Y. R.; Ma, Y.; Ellenburg, W. H.; Yang, K. S.; Qiao, Y.; Ji, H.; Xu, S.; Liu, W. R., Cellular Activities of SARS-CoV-2 Main Protease Inhibitors Reveal Their Unique Characteristics. bioRxiv 2021, 2021.06.08.447613.

14. Qiao, J.; Li, Y. S.; Zeng, R.; Liu, F. L.; Luo, R. H.; Huang, C.; Wang, Y. F.; Zhang, J.; Quan, B.; Shen, C.; Mao, X.; Liu, X.; Sun, W.; Yang, W.; Ni, X.; Wang, K.; Xu, L.; Duan, Z. L.; Zou, Q. C.; Zhang, H. L.; Qu, W.; Long, Y. H.; Li, M. H.; Yang, R. C.; Liu, X.; You, J.; Zhou, Y.; Yao, R.; Li, W. P.; Liu, J. M.; Chen, P.; Liu, Y.; Lin, G. F.; Yang, X.; Zou, J.; Li, L.; Hu, Y.; Lu, G. W.; Li, W. M.; Wei, Y. Q.; Zheng, Y. T.; Lei, J.; Yang, S., SARS-CoV-2 M(pro) inhibitors with antiviral activity in a transgenic mouse model. Science 2021, 371 (6536), 1374-1378.

15. Dampalla, C. S.; Zheng, J.; Perera, K. D.; Wong, L.-Y. R.; Meyerholz, D. K.; Nguyen, H. N.; Kashipathy, M. M.; Battaile, K. P.; Lovell, S.; Kim, Y.; Perlman, S.; Groutas, W. C.; Chang, K.-O., Postinfection treatment with a protease inhibitor increases survival of mice with a fatal SARS-CoV-2 infection. Proc Natl Acad Sci U S A 2021, 118 (29), e2101555118.

16. Cáceres, C. J.; Cardenas-Garcia, S.; Carnaccini, S.; Seibert, B.; Rajao, D. S.; Wang, J.; Perez, D. R., Efficacy of GC-376 against SARS-CoV-2 virus infection in the K18 hACE2 transgenic mouse model. Sci Rep 2021, 11 (1), 9609.

17. Boras, B.; Jones, R. M.; Anson, B. J.; Arenson, D.; Aschenbrenner, L.; Bakowski, M. A.; Beutler, N.; Binder, J.; Chen, E.; Eng, H.; Hammond, H.; Hammond, J.; Haupt, R. E.; Hoffman, R.; Kadar, E. P.; Kania, R.; Kimoto, E.; Kirkpatrick, M. G.; Lanyon, L.; Lendy, E. K.; Lillis, J. R.; Logue, J.; Luthra, S. A.; Ma, C.; Mason, S. W.; McGrath, M. E.; Noell, S.; Obach, R. S.; O’ Brien, M. N.; O’Connor, R.; Ogilvie, K.; Owen, D.; Pettersson, M.; Reese, M. R.; Rogers, T. F.; Rosales, R.; Rossulek, M. I.; Sathish, J. G.; Shirai, N.; Steppan, C.; Ticehurst, M.; Updyke, L. W.; Weston, S.; Zhu, Y.; White, K. M.; García-Sastre, A.; Wang, J.; Chatterjee, A. K.; Mesecar, A. D.; Frieman, M. B.; Anderson, A. S.; Allerton, C., Preclinical characterization of an intravenous coronavirus 3CL protease inhibitor for the potential treatment of COVID19. Nat Commun 2021, 12 (1), 6055.

18. Owen, D. R.; Allerton, C. M. N.; Anderson, A. S.; Aschenbrenner, L.; Avery, M.; Berritt, S.; Boras, B.; Cardin, R. D.; Carlo, A.; Coffman, K. J.; Dantonio, A.; Di, L.; Eng, H.; Ferre, R.; Gajiwala, K. S.; Gibson, S. A.; Greasley, S. E.; Hurst, B. L.; Kadar, E. P.; Kalgutkar, A. S.; Lee, J. C.; Lee, J.; Liu, W.; Mason, S. W.; Noell, S.; Novak, J. J.; Obach, R. S.; Ogilvie, K.; Patel, N. C.; Pettersson, M.; Rai, D. K.; Reese, M. R.; Sammons, M. F.; Sathish, J. G.; Singh, R. S. P.; 
Steppan, C. M.; Stewart, A. E.; Tuttle, J. B.; Updyke, L.; Verhoest, P. R.; Wei, L.; Yang, Q.; Zhu, Y., An oral SARS-CoV-2 M ${ }^{\text {pro }}$ inhibitor clinical candidate for the treatment of COVID-19. Science 2021, eabl4784.

19. Freitas, B. T.; Durie, I. A.; Murray, J.; Longo, J. E.; Miller, H. C.; Crich, D.; Hogan, R. J.; Tripp, R. A.; Pegan, S. D., Characterization and Noncovalent Inhibition of the Deubiquitinase and deISGylase Activity of SARS-CoV-2 Papain-Like Protease. ACS Infect Dis 2020, 6 (8), 2099-2109.

20. Shin, D.; Mukherjee, R.; Grewe, D.; Bojkova, D.; Baek, K.; Bhattacharya, A.; Schulz, L.; Widera, M.; Mehdipour, A. R.; Tascher, G.; Geurink, P. P.; Wilhelm, A.; van der Heden van Noort, G. J.; Ovaa, H.; Müller, S.; Knobeloch, K.-P.; Rajalingam, K.; Schulman, B. A.; Cinatl, J.; Hummer, G.; Ciesek, S.; Dikic, I., Papain-like protease regulates SARS-CoV-2 viral spread and innate immunity. Nature 2020, 587 (7835), 657-662.

21. Klemm, T.; Ebert, G.; Calleja, D. J.; Allison, C. C.; Richardson, L. W.; Bernardini, J. P.; Lu, B. G.; Kuchel, N. W.; Grohmann, C.; Shibata, Y.; Gan, Z. Y.; Cooney, J. P.; Doerflinger, M.; Au, A. E.; Blackmore, T. R.; van der Heden van Noort, G. J.; Geurink, P. P.; Ovaa, H.; Newman, J.; Riboldi-Tunnicliffe, A.; Czabotar, P. E.; Mitchell, J. P.; Feltham, R.; Lechtenberg, B. C.; Lowes, K. N.; Dewson, G.; Pellegrini, M.; Lessene, G.; Komander, D., Mechanism and inhibition of the papain-like protease, PLpro, of SARS-CoV-2. EMBO J 2020, 39 (18), e106275.

22. Baez-Santos, Y. M.; St John, S. E.; Mesecar, A. D., The SARS-coronavirus papain-like protease: structure, function and inhibition by designed antiviral compounds. Antiviral Res 2015, 115, 21-38.

23. Shen, Z.; Ratia, K.; Cooper, L.; Kong, D.; Lee, H.; Kwon, Y.; Li, Y.; Alqarni, S.; Huang, F.; Dubrovskyi, O.; Rong, L.; Thatcher, G. R. J.; Xiong, R., Design of SARS-CoV-2 PLpro Inhibitors for COVID-19 Antiviral Therapy Leveraging Binding Cooperativity. J Med Chem 2021, 10.1021/acs.jmedchem.1c01307.

24. Shan, H.; Liu, J.; Shen, J.; Dai, J.; Xu, G.; Lu, K.; Han, C.; Wang, Y.; Xu, X.; Tong, Y.; Xiang, H.; Ai, Z.; Zhuang, G.; Hu, J.; Zhang, Z.; Li, Y.; Pan, L.; Tan, L., Development of potent and selective inhibitors targeting the papain-like protease of SARS-CoV-2. Cell Chem Biol 2021, 28 (6), 855-865.e9.

25. Osipiuk, J.; Azizi, S. A.; Dvorkin, S.; Endres, M.; Jedrzejczak, R.; Jones, K. A.; Kang, S.; Kathayat, R. S.; Kim, Y.; Lisnyak, V. G.; Maki, S. L.; Nicolaescu, V.; Taylor, C. A.; Tesar, C.; Zhang, Y. A.; Zhou, Z.; Randall, G.; Michalska, K.; Snyder, S. A.; Dickinson, B. C.; Joachimiak, A., Structure of papain-like protease from SARS-CoV-2 and its complexes with non-covalent inhibitors. Nat Commun 2021, 12 (1), 743. 
26. Rut, W.; Lv, Z.; Zmudzinski, M.; Patchett, S.; Nayak, D.; Snipas, S. J.; El Oualid, F.; Huang, T. T.; Bekes, M.; Drag, M.; Olsen, S. K., Activity profiling and crystal structures of inhibitor-bound SARS-CoV-2 papain-like protease: A framework for anti-COVID-19 drug design. Sci Adv 2020, 6 (42), eabd4596.

27. Cho, C.-C.; Li, S. G.; Lalonde, T. J.; Yang, K. S.; Yu, G.; Qiao, Y.; Xu, S.; Ray Liu, W., Drug Repurposing for the SARS-CoV-2 Papain-Like Protease. ChemMedChem 2021, $10.1002 / c m d c .202100455$.

28. Lim, C. T.; Tan, K. W.; Wu, M.; Ulferts, R.; Armstrong, L. A.; Ozono, E.; Drury, L. S.; Milligan, J. C.; Zeisner, T. U.; Zeng, J.; Weissmann, F.; Canal, B.; Bineva-Todd, G.; Howell, M.; O'Reilly, N.; Beale, R.; Kulathu, Y.; Labib, K.; Diffley, J. F. X., Identifying SARS-CoV-2 antiviral compounds by screening for small molecule inhibitors of Nsp3 papain-like protease. Biochem $J$ 2021, 478 (13), 2517-2531.

29. Zhao, Y.; Du, X.; Duan, Y.; Pan, X.; Sun, Y.; You, T.; Han, L.; Jin, Z.; Shang, W.; Yu, J.; Guo, H.; Liu, Q.; Wu, Y.; Peng, C.; Wang, J.; Zhu, C.; Yang, X.; Yang, K.; Lei, Y.; Guddat, L. W.; Xu, W.; Xiao, G.; Sun, L.; Zhang, L.; Rao, Z.; Yang, H., High-throughput screening identifies established drugs as SARS-CoV-2 PLpro inhibitors. Protein Cell 2021, 12 (11), 877-888.

30. Swaim, C. D.; Dwivedi, V.; Perng, Y.-C.; Zhao, X.; Canadeo, L. A.; Harastani, H. H.; Darling, T. L.; Boon, A. C. M.; Lenschow, D. J.; Kulkarni, V.; Huibregtse, J. M., 6-Thioguanine blocks SARS-CoV-2 replication by inhibition of PLpro. iScience 2021, 24 (10), 103213.

31. Fu, Z.; Huang, B.; Tang, J.; Liu, S.; Liu, M.; Ye, Y.; Liu, Z.; Xiong, Y.; Zhu, W.; Cao, D.; Li, J.; Niu, X.; Zhou, H.; Zhao, Y. J.; Zhang, G.; Huang, H., The complex structure of GRL0617 and SARS-CoV-2 PLpro reveals a hot spot for antiviral drug discovery. Nat Commun 2021, 12 (1), 488.

32. Pushpakom, S.; lorio, F.; Eyers, P. A.; Escott, K. J.; Hopper, S.; Wells, A.; Doig, A.; Guilliams, T.; Latimer, J.; McNamee, C.; Norris, A.; Sanseau, P.; Cavalla, D.; Pirmohamed, M., Drug repurposing: progress, challenges and recommendations. Nat Rev Drug Discov 2019, 18 (1), 41-58.

33. Mercorelli, B.; Palù, G.; Loregian, A., Drug Repurposing for Viral Infectious Diseases: How Far Are We? Trends Microbiol 2018, 26 (10), 865-876.

34. Park, J.-Y.; Kim, J. H.; Kim, Y. M.; Jeong, H. J.; Kim, D. W.; Park, K. H.; Kwon, H.-J.; Park, S.-J.; Lee, W. S.; Ryu, Y. B., Tanshinones as selective and slow-binding inhibitors for SARS-CoV cysteine proteases. Bioorg Med Chem 2012, 20 (19), 5928-5935. 
35. Chen, X.; Chou, C.-Y.; Chang, G.-G., Thiopurine Analogue Inhibitors of Severe Acute Respiratory Syndrome-Coronavirus Papain-Like Protease, a Deubiquitinating and delSGylating Enzyme. Antivir Chem Chemother 2009, 19 (4), 151-156.

36. Chou, C.-Y.; Chien, C.-H.; Han, Y.-S.; Prebanda, M. T.; Hsieh, H.-P.; Turk, B.; Chang, G.-G.; Chen, X., Thiopurine analogues inhibit papain-like protease of severe acute respiratory syndrome coronavirus. Biochem Pharmacol 2008, 75 (8), 1601-1609.

37. Cheng, K.-W.; Cheng, S.-C.; Chen, W.-Y.; Lin, M.-H.; Chuang, S.-J.; Cheng, I. H.; Sun, C.-Y.; Chou, C.-Y., Thiopurine analogs and mycophenolic acid synergistically inhibit the papainlike protease of Middle East respiratory syndrome coronavirus. Antiviral Res 2015, 115, 9-16. 
bioRxiv preprint doi: https://doi.org/10.1101/2021.11.04.467342; this version posted November 5, 2021. The copyright holder for this preprint (which was not certified by peer review) is the author/funder, who has granted bioRxiv a license to display the preprint in perpetuity. It is made available under aCC-BY 4.0 International license.

For Table of Contents Use Only

Validation and invalidation of SARS-CoV-2 papain-like protease inhibitors

Chunlong Ma, ${ }^{\dagger}$ Jun Wang ${ }^{\dagger, *}$

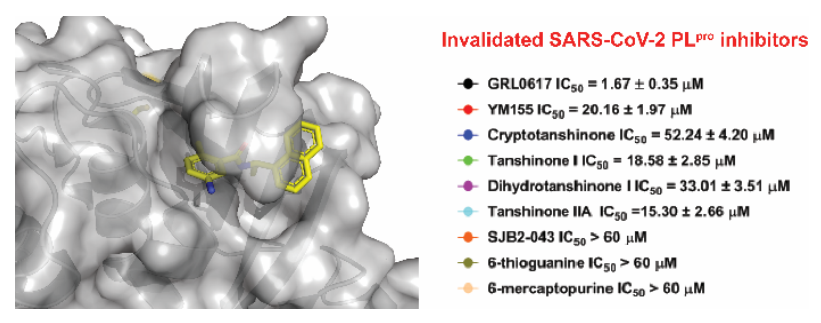

